\title{
Privileges of Pharmacists in Saudi Arabia: Drug Monitoring and Providing Education to Healthcare Professionals
}

Faisal Al-Otaibi, Ph. D, Assistant Professor, College of Pharmacy, Pharmacy Patrice Department, Shaqra University, Saudi Arabia. Mohamed Soliman Imam, Ph. D, Assistant Professor, Dean, College of Pharmacy, Shaqra University, Saudi Arabia.

Randa Mansour Abdel-Sattar Ahmed, Ph.D, Biomedical Science Department, College of Pharmacy, Shaqra University, Saudi Arabia.

Amsha Alotaibi, Pharm D, Clinical Pharmacist, College of Pharmacy, Pharmacy Patrice Department, Shaqra University, Riyadh, Saudi Arabia.

Asma Alotaibi, Pharm D, Clinical Pharmacist, College of Pharmacy, Pharmacy Practice Department, Shaqra University, Saudi Arabia. Amal Alotaibi, Pharm D, Clinical Pharmacist, College of Pharmacy, Shaqra University, Saudi Arabia.

Wesam Alsuwaid, Pharm D, Clinical Pharmacist, College of Pharmacy, Pharmacy Practice Department, Shaqra University, Saudi Arabia. Yousef Ahmed Alomi*, iD BSc. Pharm, MSc. Clin Pharm, BCPS, BCNSP, DiBA, CDE, Critical Care Clinical Pharmacists, TPN Clinical Pharmacist, Freelancer Business Planner, Content Editor and Data Analyst, P.O.BOX 100, Riyadh, Saudi Arabia.

\section{Correspondence:}

Dr. Yousef Ahmed Alomi, BSc. Pharm, MSC. Clin Pharm, BCPS, BCNSP, DiBA, CDE Critical Care Clinical Pharmacists, TPN Clinical Pharmacist, Freelancer Business Planner, Content Editor and Data Analyst, P.O.BOX 100, Riyadh 11392, Riyadh, Saudi Arabia.

Phone no: +966504417712 E-mail: yalomi@gmail.com

Received: 20-07-2019;

Accepted: 20-10-2019.

Copyright: (c) the author(s),publisher and licensee Pharmacology, Toxicology and Biomedical Reports. This is an open-access article distributed under the terms of the Creative Commons Attribution NonCommercial License, which permits unrestricted non-commercial use, distribution, and reproduction in any medium, provided the original work is properly cited.

This is an open access article distributed under the terms of the Creative Commons Attribution-NonCommercial-ShareAlike 4.0 License

Access this article online

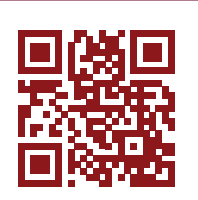

www.ptbreports.org

DOI:

10.5530/PTB.2020.6.10

\begin{abstract}
Objectives: To explore the privileges of pharmacists with regard to the drug monitoring and providing education to healthcare professionals in Saudi Arabia. Methods: This is a 4-month cross-sectional survey regarding drug monitoring and providing education to healthcare professionals in Saudi Arabia. The study consisted of two parts: the first part collected demographic information and the second part comprised a questionnaire with 28 questions divided into 4 domains. The questions were derived from previous literature and from the regulatory standards of the American Society of Health-System Pharmacists (ASHP). The four domains were as follows: management and resources, pharmacist prescribing and therapeutic interchange, clinical and administration privilege and drug monitoring and healthcare education. The responses were obtained using a 5-point Likert response scale system with close- and open-ended questions. The survey questionnaire was distributed in an electronic format to the director of pharmacy. In this study, we analyzed pharmacist's privilege with regard to drug monitoring and the education of healthcare providers. All data were obtained through the Survey Monkey system. Results: The survey was distributed to 36 hospitals. Most of the pharmacist's privilege in drug monitoring and documentation of the clinical impact and cost avoidance was related to patient counseling $(90.63 \%)$, adverse drug reactions $(88.24 \%)$ and drug quality reporting $(87.50 \%)$. Most of the candidates were students from Diploma in Pharmacy $(50.00 \%)$ followed by $(47.22 \%)$ pharmacy student and $(44.44 \%)$ pharmacy technician. Majority of the pharmacists having privileges in providing education and training was available for pharmacists and clinical pharmacists. Finally, pharmacy technicians delivered most of the education and training to general physicians, nurses and specialist physicians. Conclusion: In Saudi Arabia, privileges of a pharmacist with regard to drug monitoring do not exist in various departments of hospitals such as neonates, pediatrics and geriatrics patients. Regular and clinical pharmacists had most of the privileges in providing education and training to the healthcare professionals and few of the healthcare professionals received education and training by the pharmacists. Therefore, there is an increasing demand of a comprehensive awareness program about privileges of a pharmacist in the Kingdom of Saudi Arabia.

Key words: Privileges, Pharmacists, Drug Monitoring, Education, Healthcare, Professionals,

Saudi Arabia.
\end{abstract}

\section{INTRODUCTION}

The role of pharmacists has been expanding in the last few years, which involves different areas that define patient-centered care as the primary objective. ${ }^{1,2}$ The pharmacist's presence in the hospital ensures the safe and effective use of medicines. Furthermore, the participation of pharmacists in drug therapy management improves outcomes of drug therapy, facilitates patient adherence to therapy and increases the effectiveness of treatment. ${ }^{3}$ Providing patient education and counseling improves therapeutic outcomes, patient compliance and quality of life as well as increases patient's perception about medication and lifestyle modifications in chronic diseases. ${ }^{4}$ Due to the increase in wages, most Saudi pharmacists end up practicing in hospital settings rather than in retail pharmacies. The role of hospital staff pharmacists includes the management of medication storage and supplies, medication verification and dispensing, provision of drug information to other healthcare providers and training of students and residents. ${ }^{5}$ In addition, they participate in sterile preparation of chemotherapy or medications and are involved in the identification and reporting of adverse drug events (ADEs). ${ }^{5}$ Most of the hospitals have an ADR reporting program, a medication error reporting program and a multidisciplinary medication safety committee. ${ }^{6,7}$ The committee's tasks are to analyze the reported ADRs and medication errors and create a modified system or policies to avoid further errors in the pharmacy department. ${ }^{6}$ Many hospitals in Saudi Arabia are accredited by the Joint Commission International, where the hospitals are aware of the importance of quality for improving healthcare. Quality indicators such as the number of prescriptions filled, patient satisfaction, patient's waiting time, number of dispensing errors and others are measured, where the services are modified based on their outcomes. ${ }^{8}$ The pharmacists play a critical role in developing the healthcare system through their involvement in the successful use of pharmacological therapies, medication safety activities, enhancing therapeutic plans along with patient counseling, increased patient adherence and practical cooperation within the medical team. ${ }^{9}$ 15 ASHP national survey (2015) divided drug monitoring and patient counseling into a wide variety of activities such as handling of cases of 
ADRs, identification of patients requiring monitoring, monitoring orders for inpatients and pharmacist performance inpatient counseling in the outpatient pharmacy. ${ }^{16}$ A previous study has focused on the pharmacy practice with an emphasis on drug monitoring and patient education in a local setting, however, it was conducted with limited number of hospitals in the Riyadh region. ${ }^{3}$ Another detailed study discussed about drug monitoring in 100 hospitals located at various regions in Saudi Arabia. ${ }^{7}$ Previous studies have only discussed the pattern of drug monitoring and education of healthcare providers, whereas no study has focused on pharmacists' privileges with regard to drug monitoring and providing education to healthcare professionals. Therefore, in this study, we aimed to explore the privileges of a pharmacist with emphasis on drug monitoring and providing education to healthcare professionals in the Kingdom of Saudi Arabia (KSA).

\section{METHODS}

This is a 4-month cross-sectional survey regarding privileges of pharmacists in Saudi Arabia. The study consisted of two parts: the first part collects demographic information and the second part comprises a questionnaire with 28 questions divided into 4 domains: These domains are derived from previous literature and from the guidelines and regulations stated by the ASHP. ${ }^{17-21}$ The four domains are as follows: privilege management and resources, pharmacist prescribing and therapeutic interchange, clinical and administrative privilege and drug monitoring and healthcare education. The responses were obtained via a 5-point Likert response scale system with close- and open-ended questions. The survey was distributed in an electronic format and was distributed to the director of hospital pharmacy, deputy director, or to the pharmacy quality management. The follow-up was done via email and telephone after every 1-2 weeks. All primary healthcare centers and regional pharmacy administration at $\mathrm{MOH}$ were excluded from the study. In this study, we analyzed privilege of a pharmacist with respect to drug monitoring and providing education and training to healthcare professionals. All data were obtained through the Survey Monkey system and analyzed using Statistical Package of Social Sciences (SPSS) version 20. The data were validated by 3 methods; three authors reviewed the survey independently. The pilot distribution of the survey had been done and the survey correct accordingly. Cronbach's alpha was calculated to test the internal validity. The survey was exempted from the international guidelines of institutional review boards (IRB). ${ }^{22}$

\section{RESULTS}

The survey was distributed to 36 hospitals. Of them, $19.44 \%$ of the hospitals had $100-199$ beds and had $<50$ beds, while $13.89 \%$ had $50-99$ beds, 300-399 beds and $\geq 600$ beds) hospitals. Of the total 36 hospitals, 18 (50.00\%) were accredited by the CBAHI, 17 (47.22\%) were accredited by the Saudi Commission of Health Specialties and 13 (36.11\%) were accredited by the Joint Commission, whereas 5 (13.89\%) hospitals had no accreditation by any organization and 13 (36.11\%) hospitals had their $50-74 \%$ of the patients covered by a health insurance. The majority of the responders were in the age group of $41-65$ years $(17$ (47.22\%)). Majority of the responders were Saudi (32 (88.89\%)) and non-Saudi (4 (11.11\%)) nationals. Most of the responders had a degree of Diploma in Pharmacy (14 (38.89\%)) and the Bachelor of Science in Pharmacy (12 (33.33\%)). Most of the responders had $<1$ year $(46.67 \%)$ experience in pharmacy, whereas $30.77 \%$ of the responders had $4-6$ years of experience in clinical pharmacy and $43.75 \%$ had $>6$ years of experience in pharmacy administration (Tables 1 and 2). Most of the privileges related to the drug monitoring and documentation of the clinical impact and cost avoidance was for patient counseling (90.63\%) and ADRs (88.24\%) followed by drug quality reporting $(87.50 \%)$, nonformulary requests $(84.85 \%)$ and drug information inquiries (82.35\%). Most of the privileges were related to the documentation of ADRs for neonatal patients $(41.18 \%)$ and nonformulary requests (39.39\%), whereas in the case of pediatrics, most of the privileges were related to the documentation of patient counseling (59.38\%) and drug quality reporting (56.25\%). In the case of adult patients, the privileges were related to patient counseling $(84.38 \%)$ and pharmacist intervention $(75.76 \%)$ and in geriatrics patients, it was patient counseling $(46.88 \%)$, nonformulary requests $(45.45 \%)$ and pharmacist intervention (45.45\%) (Table 3). Most of the pharmacists had the privilege to provide education and training to Diploma in Pharmacy students $(18(50.00 \%))$ followed by Pharmacy students (17 (47.22\%)) and pharmacy technician (16 (44.44\%)) (Table 4$)$. The majority of the privilege of a pharmacist in providing education and training was for pharmacist (111) followed by clinical pharmacists (77) and pharmacy technician (63) periodically, whereas most of the education and training was delivered to the following healthcare professionals by the pharmacy staff: general physician (71), nurses (52) and specialist physicians (46) periodically (Tables 5 and 6). The Cronbach's alpha test results was 0.983 .

\section{DISCUSSION}

The General Administration of Pharmaceutical Care at MOH in KSA released the updated pharmacy strategic plan with an emphasis on essential pharmaceutical care services and advanced clinical pharmacy services including patient medication counseling and drug therapy monitoring. ${ }^{23}$ The strategic plan consisted of several phases, which also included the implementation phase. During this phase, the task force committee is responsible for establishing more than 30 pharmacy practice programs that are patient-centric. For instance, medications safety program takes care of the detection and prevention of medication errors by taking care of ADRs. Furthermore, the programs include all elements of Institution of Safe Medication Practice and all requirements of medication safety standards of the CBAHI. ${ }^{24}$ In this study, we aimed to explore privileges of a pharmacist related to the drug monitoring and in providing education and training to the healthcare providers. Our results showed that most of the privileges related to the drug monitoring and documentation of the clinical impact and cost avoidance was recorded for patient counseling and ADRs. The results of drug monitoring was better than those that has been reported by Alomi et al. ${ }^{7}$ and lower than those that was reported by Pedersen et al. ${ }^{16}$ This result is expected because of the good implementation of medications safety program; however, our results were lower than that reported in the USA because the program was started recently. ${ }^{3,16}$ More than half of hospital pharmacies ensure that the clinical effectiveness of cost avoidance of drug monitoring activities is measured. This is expected because the pharmacy administration began to measure the effectiveness of pharmacy services through clinical and economic outcomes. The implementation of pharmacy research is insufficient, which is due to the poor knowledge and inadequate experience related to scientific research, which is reported by Alomi et al. ${ }^{7}$

Bachelor of Science in Pharmacy or Diploma in Pharmacy students are sent for training to most hospital pharmacies; therefore, it is normal to find an increased number of trainees every year. However, there were few pharmacy students because most of the hospitals need the accreditation by Saudi Commission for Healthcare Specialties for pharmacy residency program. However, the pharmacy residency programs were found to be better than previous study because of the expansion of the pharmacy training services in KSA. ${ }^{25}$ Pharmacist and clinical pharmacist had most of the privileges in providing education and training on a weekly basis; they could also provide short courses (5 days). However, there were not many clinical pharmacy residency programs that existed in KSA. Resident trainees were very few in this study and higher than what has been reported by Alomi et al. ${ }^{25}$ This is because hospitals have more number of Diploma students and difficult to apply for clinical pharmacy programs. 


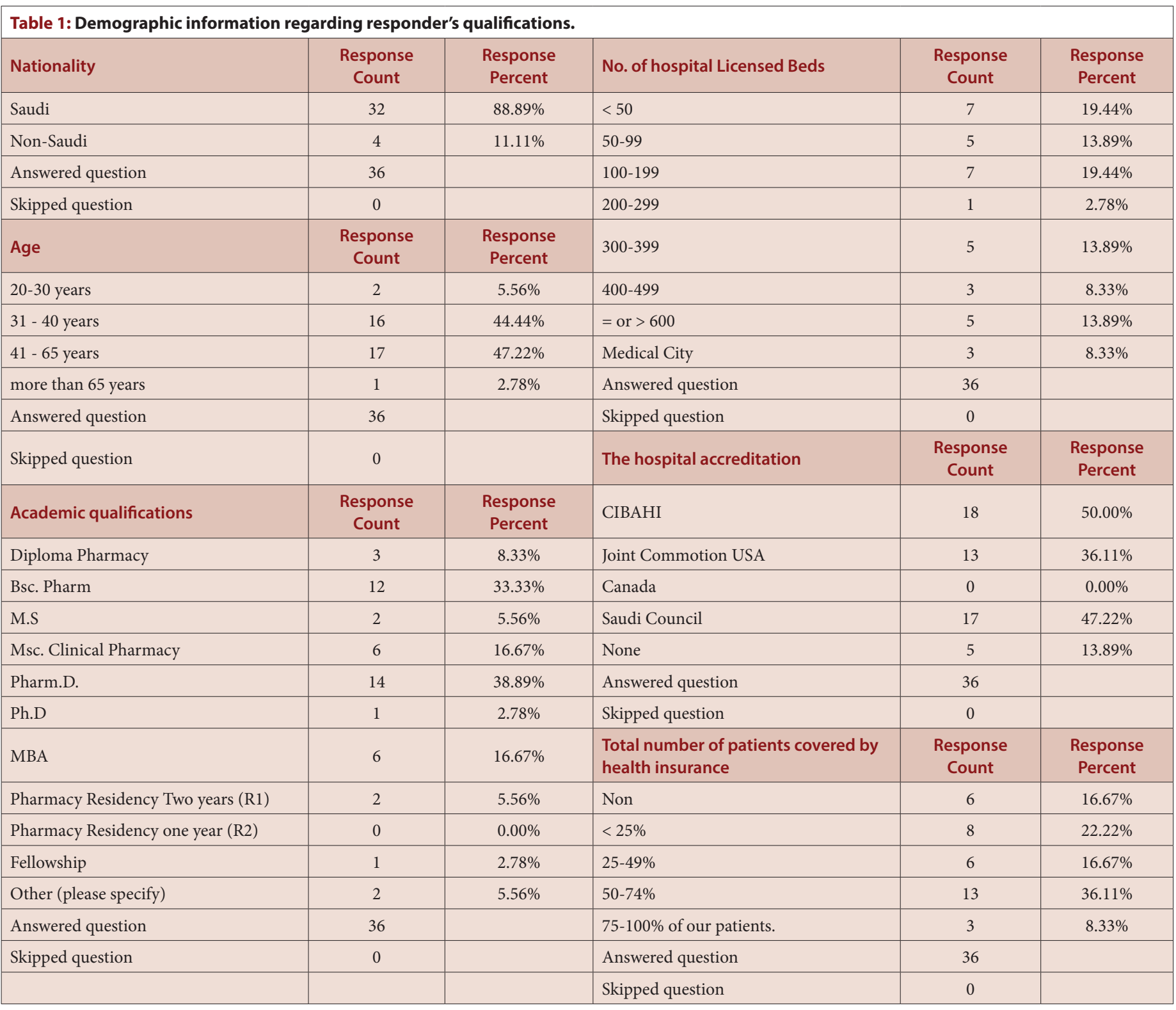

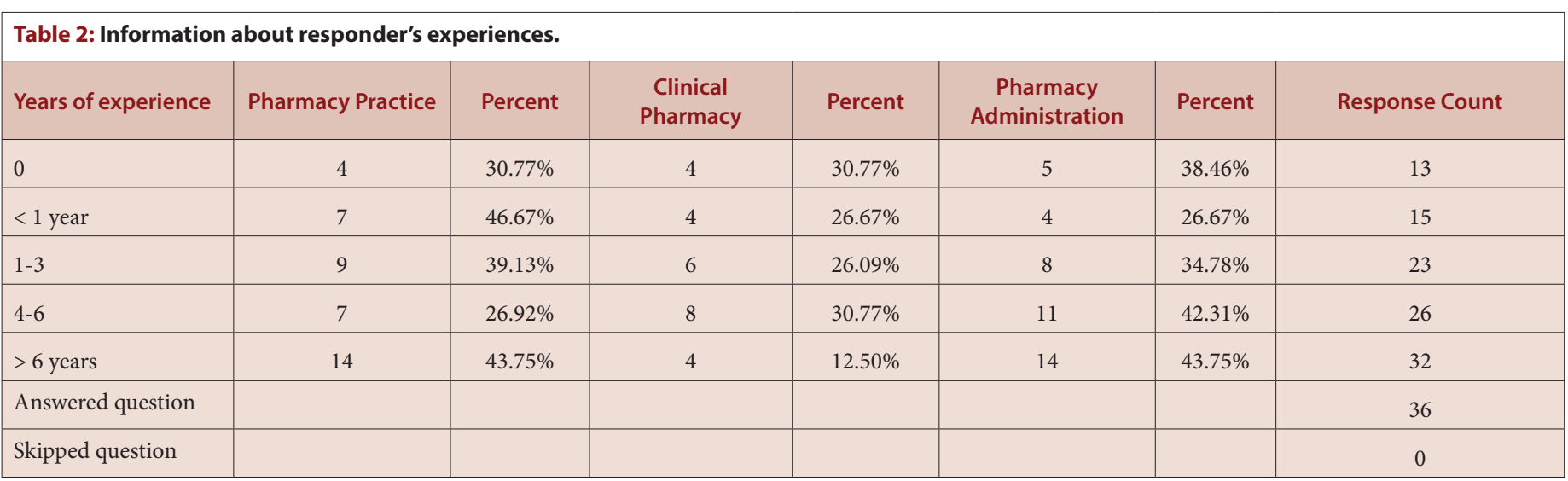

Most of the education and training programs were delivered by the pharmacist to general physicians, nurses and specialized physicians and most of the educational courses were delivered weekly for CME, orientation program and short educational courses (1-5 days). This is because of the requirements of the $\mathrm{MOH}$ or local or international accreditation organizations. ${ }^{25}$ These investigations are not done previously with these details to compare the finding with either local or international studies in term of pharmacist privilege of education and training activities and the privi- 


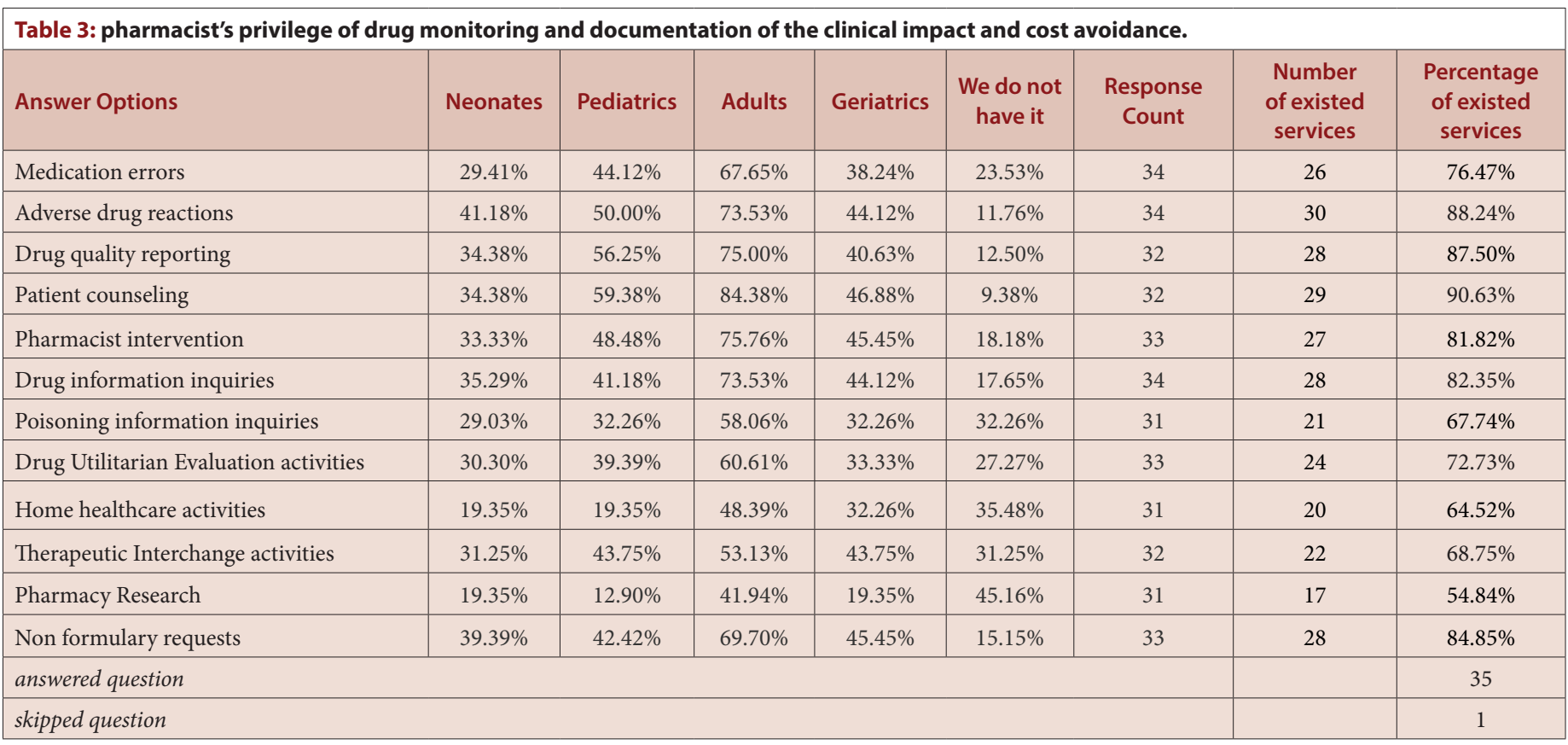

\begin{tabular}{|l|c|c|}
\hline Table 4: The hospital pharmacist's privilege in education and training for students and hospital staff. \\
\hline Answer Options & Response Count & Response Percentages \\
\hline Pharmacy Technician students & 12 & $33.33 \%$ \\
\hline Pharmacy Technician & 16 & $44.44 \%$ \\
\hline Pharmacist Student & 17 & $47.22 \%$ \\
\hline Pharm. D degree students & 18 & $50.00 \%$ \\
\hline Bsc. Pharm. (New Employee) & 10 & $27.78 \%$ \\
\hline Bsc Residency & 5 & $13.89 \%$ \\
\hline Post Pharm D or Master Residency & 9 & $25.00 \%$ \\
\hline Post Pharmacy Technician Residency & 2 & $5.56 \%$ \\
\hline Nursing school & 2 & $5.56 \%$ \\
\hline Medical school & 5 & $13.89 \%$ \\
\hline Non & 1 & $2.78 \%$ \\
\hline Answered & 36 & \\
\hline Skipped & 0 & \\
\hline
\end{tabular}

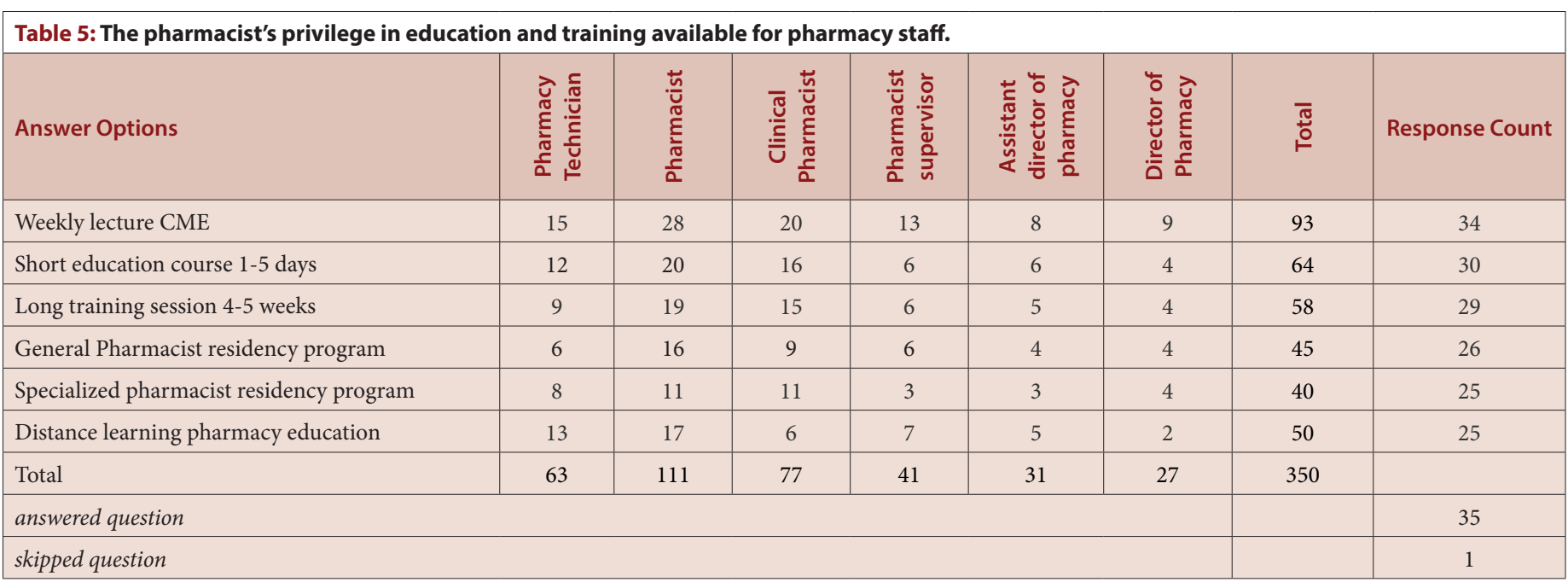




\begin{tabular}{|c|c|c|c|c|c|c|c|c|c|}
\hline Answer Options & $\begin{array}{l}\stackrel{\varpi}{~} \\
\bar{\Sigma}\end{array}$ & ڤั & 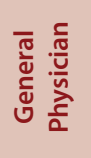 & 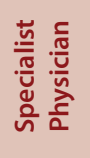 & 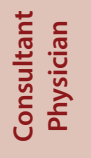 & 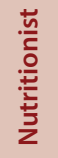 & 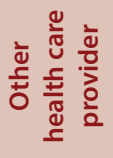 & Total & Response Count \\
\hline Weekly lecture CME & 13 & 6 & 18 & 13 & 10 & 7 & 2 & 69 & 31 \\
\hline Short education course $1-5$ days & 9 & 8 & 12 & 12 & 5 & 1 & 4 & 51 & 25 \\
\hline Orientation program & 13 & 9 & 17 & 9 & 10 & 4 & 6 & 68 & 28 \\
\hline Distance learning CME education by pharmacy & 8 & 3 & 12 & 5 & 4 & 1 & 4 & 37 & 24 \\
\hline Total & 52 & 30 & 71 & 46 & 32 & 13 & 19 & 263 & \\
\hline \multicolumn{8}{|l|}{ answered question } & & 34 \\
\hline
\end{tabular}

lege of pharmacy education and training programs at $\mathrm{MOH}$ hospitals Further studies should focus on monitoring this information every year in order to improve the services at hospital pharmacies.

\section{CONCLUSION}

Two-thirds of the privileges of the pharmacist is given to monitoring drug therapy and one-third on education and training in the KSA. Majority of the privilege related to drug therapy monitoring activities were common with few improvements. Further studies should target a comprehensive review of pharmacist's privilege with regard to drug therapy monitoring and education and training in KSA.

\section{ACKNOWLEDGEMENT}

None.

\section{CONFLICT OF INTEREST}

The authors declare no conflict of interest.

\section{ABBREVIATIONS}

ADRs: adverse drug reactions; CME: continuing medical education; MOH: Ministry of Health; KSA: Kingdom of Saudi Arabia; CBAHI: Saudi Central Board for Healthcare Accreditation; ASHP: American Society of Health-System Pharmacists; SPSS: Statistical Package of Social Sciences.

\section{REFERENCES}

1. American Society of Hospital Pharmacists. Draft statement on pharmaceutical care. American Journal of Hospital Pharmacy. 1993;50(1):126-8.

2. American Society of Health-System Pharmacists. ASHP guidelines on a standardized method for pharmaceutical care. Am J Heal Pharm. 1996;53(14):1713-

3. Alsultan MS, Mayet AY, Khurshid F, Al-jedai AH. Hospital pharmacy practice in Saudi Arabia: Drug monitoring and patient education in the Riyadh region. Saudi Pharm J. 2013;21(4):361-70.

4. Malathy R, Narmadha MP, Ramesh S, Alvin JM, Dinesh BN. Effect of a diabetes counseling programme on knowledge, attitude and practice among diabetic patients in Erode district of South India. J Young Pharm. 2011;3(1):65-72.

5. Alomi YA, Jamaan AS, Abdullah AR, Shorog E, Alshahran A, Alasmary S, et al. National Survey of Pharmacy Practice at MOH Hospitals in Saudi Arabia 20162017: Preparation of Medications and Dispensing. J Pharm Pract Community Med. 2018;4(1s):s54-9

6. Alomi YA, Alghamdi SJ, Alattyh RA. National Survey of Pharmacy Practice at MOH Hospitals in Saudi Arabia 2016-2017: Clinical Pharmacy Services. J Pharm Pr Community Med. 2018;4(1):1S-8S.

7. Alomi YA, Shorog E, Alshahrani A, Alasmary S, Alenazi H, Almutairi A, et al. National Survey of Pharmacy Practice at MOH Hospitals in Saudi Arabia 20162017: Drug Monitoring and Patients Education. J Pharm Pract Community Med. 2018;4(1s):s17-22.
8. Al-Jedai A, Qaisi S, Al-Meman A. Pharmacy practice and the health care system in Saudi Arabia. Canadian Journal of Hospital Pharmacy. Canadian Society of Hospital Pharmacists. 2016;69(3):231-7.

9. Alomi YA, Aldosori N, Alhadab M, Alotaibi NR, Al-Shubbar N, Al-Enazi ADM et al. The Outcomes of Clinical Pharmacist Consultation Visits at Ministry of Health Hospitals in Saudi Arabia: Medication Safety and Pharmacy Research. $J$ Pharm Pract Community Med. 2017;3(3):168-75

10. Alomi YA, Aldosori N, Alhadab M, Alotaibi NR, Al-Shubbar N, AlotaibiT, et al. The Value of Clinical Pharmacist Consultation Visits at Ministry of Health Hospitals in Saudi Arabia: Intravenous Admixture Services and Pharmacy Total Quality Management. J Pharm Pract Community Med. 2017;3(3):161-167.

11. Alomi YA Aldosori $N$, Alhadab $M$, Alotaibi NR, Al-Shubbar N, Jadkarim MM, et al. Impact of Clinical Pharmacist Consultation Visits at Ministry of Health Hospitals in Saudi Arabia: Clinical Pharmacy Services and Pharmacy Workforce. $J$ Pharm Pract Community Med. 2017;3(3):154-160.

12. Alomi YA, Alshabaar N, Lubad N, Albusalih FA. Inpatient Medication Errors and Pharmacist Intervention at Ministry of Health Public Hospital, Riyadh, Saudi Arabia. Pharmacol Toxicol Biomed Reports. 2019;5(1):44-8.

13. Alanazi1 AA, Alomi YA, Almaznai MM, Aldwihi M, Aloraifi IAK, Albusalih FA Pharmacist's Intervention and Medication Errors Prevention at Pediatrics, Obstetrics and Gynecology Hospital in East Province, Saudi Arabia. Int J Pharm Heal Sci. 2019;2(2):122-8.

14. Alomi1 YA, Fallatah AO, Al-Shubaar N, Qohal AA, Alameer LY. The Clinical Outcomes of Pharmacist Interventions in Total Parenteral Nutrition services in Riyadh City, Saudi Arabia. Int J Pharm Heal Sci. 2019;2(2):135-40.

15. Alomi YA, Fallatah AO, Bahadig FA, Qahtani AAAL. The Economic Outcomes of Pharmacist Interventions in Total Parenteral Nutrition Services in Saudi Arabia. Pharmacol Toxicol Biomed Reports. 2019;5(3s):S40-9.

16. Pedersen CA, Schneider PJ, Scheckelhoff DJ. ASHP national survey of pharmacy practice in hospital settings: Monitoring and patient education: 2015. Am J Heal Pharm. 2016;73(17):1307-30.

17. Burns AL. Credentialing and Privileging of Pharmacists: A Resource Paper from the Council on Credentialing in Pharmacy Council. Consult Pharm. 2015;29(11):757-70.

18. Guirguis LM, Hughes CA, Makowsky MJ, Sadowski CA, Schindel TJ, Yukse N. Survey of pharmacist prescribing practices in Alberta. Am J Heal Pharm. 2017;74(2):62-9

19. Jordan TA, Hennenfent JA, Lewin JJ, Nesbit TW, Weber R. Elevating pharmacists' scope of practice through a health-system clinical privileging process. Am J Heal Pharm. 2016;73(18):1395-405.

20. Blair MM, Carmichael J, Young E, Thrasher K. Pharmacist privileging in a health system: Report of the Qualified Provider Model Ad Hoc Committee. Am J Hea Pharm. 2007;64(22):2373-81.

21. Christel GS. Clinical Pharmacist Credentialing and Privileging: A Process for Ensuring High-Quality Patient Care. Parctioner Forum. 2019;36(4):155-7.

22. The Office for Human Research Protections. Human Subject Regulations Decision Charts. Chart. 2016. [cited 2019 Nov 4]. Available from: https://www.hhs. gov/ohrp/regulations-and-policy/decision-charts/index.html

23. Alomi YA, Alghamdi SJ, Alattyh RA. Strategic Plan of General Administration of Pharmaceutical Care at Ministry of Health in Saudi Arabia 2012 - 2022. J Pharm Pharm Scien. 2015;1(13):1-8.

24. Alomi YA. National Medication Safety Program at Ministry of Health in Saudi Arabia. J Pharmacovigil. 2015;3(5):e145.

25. Yousef AA, Saeed JARAA. National Survey of Pharmacy Practice at MOH Hospitals in Saudi Arabia 2016-2017: Pharmacy Education and Training. J Pharm Pr Community Med. 2018;4(1):1S-8S 